\title{
GAMBARAN GIGI IMPAKSI PASIEN YANG BERKUNJUNG DI BP-RSGM UNIVERSITAS SAM RATULANGI PADA TAHUN 2011
}

\author{
${ }^{1}$ Prof. dr. J.M.L Umboh, ${ }^{1}$ drg. Lenny Winata, M.kes, ${ }^{2}$ Dwayne J.Riwudjeru \\ ${ }^{1}$ Program Studi Kedokteran Gigi \\ ${ }^{2}$ Mahasiswa Program Studi Kedokteran Gigi Fakultas Kedokteran Universitas Sam Ratulangi
}

\begin{abstract}
ABSTRAK
Gigi impaksi adalah keadaan dimana gigi tidak erupsi padahal telah melewati waktu erupsi normal. Gigi impaksi dapat berupa erupsi sebagian atau sama sekali tidak erupsi dan berada dalam posisi yang tidak memungkinkan untuk erupsi lagi. Mengingat tingginya prevalensi gigi impaksi pada masyarakat dimana data mengenai prevalensi gigi impaksi pada masyarakat Indonesia, khususnya Kota Manado belum ditemukan, penulis menilai perlu dibuat suatu penelitian mengenai hal tersebut. Penelitian ini memberikan gambaran gigi impaksi di BP-RSGM UNSRAT pada tahun 2011. Tujuan penelitian ini ialah untuk mengetahui gambaran gigi impaksi di BP-RSGM UNSRAT pada tahun 2011. Kesimpulan yang didapat dari penelitian ini yaitu Total rekam medis pasien yang berkunjung ke BP-RSGM UNSRAT Manado yang digunakan sebagai subjek penelitian ini yaitu sebanyak 304. Impaksi lebih banyak terjadi pada perempuan yaitu sebanyak $189(62,17 \%)$ dibandingkan pada laki-laki (115 (37,82\%). Impaksi gigi paling banyak terjadi pada gigi molar ketiga maksila dengan jumlah gigi impaksi sebanyak 367 (50,34\%) impaksi gigi molar ketiga mandibula sebanyak 337 (46,22\%).
\end{abstract}

Kata kunci: impaksi, molar ketiga, partial erupted, unerupted.

\begin{abstract}
ABSTRAC
The impacted teeth is a condition in which the unerupted teeth passed the normal eruption time. Erupted tooth impaction can be partially or completely unerupted and are in a position that does not allow it to erupt again. Considering the prevalence of tooth impaction are high in the communities meanwhile the data on the prevalence of tooth impaction in Indonesian society, especially the city of Manado has not been found, the authors assess the needs of research on the matter. This research gives the picture of tooth impaction in BP-RSGM UNSRAT in 2011. The Aims To reveal the tooth impaction in BP-RSGM UNSRAT in 2011. Total medical records of patients who visited the BP-RSGM UNSRAT Manado used as the subject of this study is as much as 304. Impaction occurs more frequently in women as many as 189 (62.17\%) than in men (115 (37.82\%). Most tooth impaction occurs in the maxillary third molars impacted by the number of teeth as much as 367 (50.34\%) impacted mandibular third molar teeth as much as 337 (46.22\%).
\end{abstract}

Keywords : impaction, third molar, partial erupted, unerupted.

Korespondensi: Dwayne Riwudjeru Program Studi Kedokteran Gigi, Fakultas Kedokteran Universitas Sam Ratulangi, Manado, Indonesia. E-mail: buster_dive@yahoo.com 


\section{PENDAHULUAN}

Erupsi gigi merupakan proses fisiologi yang berhubungan dengan perkembangan akar gigi. Erupsi gigi berlangsung sebelum terjadi penutupan akar yang sempurna. Gigi impaksi adalah keadaan dimana sebagian atau seluruh gigi tidak erupsi padahal telah melewati waktu erupsi normal. Gigi tersebut pembentukan akarnya telah selesai namun tidak erupsi ke permukaan secara sempurna. ${ }^{1}$ Gigi impaksi dapat berupa erupsi sebagian atau sama sekali tidak erupsid an berada dalam posisi yang tidak memungkinkan untuk erupsi lagi. ${ }^{1,2,3}$

Prevalensi gigi impaksi telah banyak dilaporkan oleh berbagai peneliti. Grover dan Lorton melakukan pemeriksaan pada 5000 pasukan dan mendapatkan 10.000 gigi impaksi pada pasukan tersebut. ${ }^{4}$ Penelitian lain yang dilakukan oleh Ahlqwist dan Grondahl $1^{5}$ pada 1418 pasien menemukan prevalensi impaksi sebesar $8.3 \%$ dengan jumlah gigi impaksi mencapai 166 gigi dimana 141 gigi impaksi merupakan gigi molar ketiga maksila dan mandibula diikuti impaksi kaninus maksila dan mandibula sebanyak 17 gigi. Penelitian lain yang dilakukan oleh Stanley $\mathrm{dkk}^{6}$ dengan sampel penelitian sebanyak 11598 menemukan tingkat impaksi sebanyak $15,1 \%$ dengan prevalensi impaksi terbanyak pada gigi molar ketiga maksila dan mandibula yaitu sebanyak 1468 dan 2068 gigi, diikuti gigi kaninus maksila dan mandibula dengan total 166 gigi impaksi. Penelitian mengenai prevalensi gigi impaksi juga dilakukan oleh Shah $\mathrm{dkk}^{7}$ pada 7886 masyarakat Kanada menemukan adanya mpaksi sebanyak 6,9\% (918 gigi impaksi) dimana impaksi paling banyak terjadi pada gigi molar ketiga mandibula dengan jumlah 505 gigi impaksi, molar ketiga maksila sebanyak 286 gigi, kaninus maksila sebanyak 61 gigi, kaninus mandibula sebanyak 8 gigi, dan gigi impaksi selain gigi tersebut sebanyak 58 gigi. Nampaknya impaksi paling banyak terjadi pada gigi molar ketiga baik mandibula maupun maksila diikuti gigi kaninus. ${ }^{5-8}$

Mengingat tingginya prevalensi gigi impaksi pada masyarakat dimana data mengenai prevalensi gigi impaksi pada masyarakat Indonesia, khususnya Kota Manado belum ditemukan berkunjung di BP-RSGM UNSRAT selama tahun 2011 dan mencatat gigi yang tercatat sebagai partial erupted (PE) pada rekam medis dan telah satu tahun melewati waktu erupsi normal, kemudian data diolah, dianalisis dan disajikan dalam bentuk tabel.

\section{METODE}

Penelitian ini dilakukan secara deskriptif, yakni dengan mengambil data sekunder berupa rekam medis pasien yang berkunjung di BP-RSGM UNSRAT, Manado. Waktu penelitian dilakukan dari bulan AgustusSeptember 2011, Penelitian ini dilakukan di bagian rekam medik BP-RSGM UNSRAT, Manado. Populasi penelitian ini yaitu psien yang berkunjung di BP-RSGM UNSRAT Manado selama tahun 2011. Sampel penelitian yaitu seluruh pasien yang berkunjung di BP-RSGM UNSRAT Manado. Metode pengambilan sampel yang digunakan adalah Total Sampling, melihat data rekam medis yang berisi data lengkap pasien yang berkunjung di BP-RSGM UNSRAT selama tahun 2011 dan mencatat gigi yang tercatat sebagai partial erupted (PE) pada rekam medis dan telah satu tahun melewati waktu erupsi normal, kemudian data diolah, dianalisis dan disajikan dalam bentuk tabel.

\section{HASIL PENELITIAN}

Data di atas menunjukkan gigi impaksi yang terjadi pada setiap kelompok umur. Dari total gigi impaksi sebanyak 729 berdasarkan tabel 3 sebelumnya, gigi impaksi tersebut terdistribusi ke dalam 7 kelompok umur. Gigi impaksi paling banyak terjadi pada kelompok umur 18-27 tahun dimana terdapat $453(62,13 \%)$ gigi impaksi. Kelompok umur 28-37 tahun merupakan kelompok umur terbanyak kedua dengan gigi impaksi sebanyak $111(15,22 \%)$ gigi impaksi. Kelompok umur 38-47 tahun merupakan kelompok umur terbanyak ketiga dengan gigi impaksi sebanyak 83 (11,38\%). Kelompok umur lainnya yaitu 48-57 tahun berada pada urutan selanjutnya dengan gigi impaksi sebanyak 40 $(5,4 \%)$ diikuti dengan kelompok umur 58-67 tahun dengan gigi impaksi sebanyak $30(4,11 \%)$ gigi impaksi. Pada kelompok umur 68-77 tahun terdapat $11(1,50 \%)$ gigi impaksi sedangkan kelompok umur 8-17 tahun merupakan 
kelompok umur dengan jumlah gigi impaksi yang sangat sedikit yaitu hanya 1 gigi dengan persentase $(0,13 \%)$. Berdasarkan kelompok umur, didapatkan hasil bahwa gigi yang paling banyak mengalami impaksi adalah gigi molar ketiga mandibula yaitu sebanyak $222(30,45 \%)$ pada kelompok umur 18-27 tahun diikuti gigi molar ketiga maksila sebanyak $214(29,35 \%)$ gigi impaksi. Pada kelompok umur kedua terbanyak yaitu kelompok umur 28-37 tahun juga terjadi hal yang sama dimana molar ketiga mandibula lebih banyak mengalami impaksi yaitu sebanyak $56(7,68 \%)$ dibandingkan molar ketiga maksila sebanyak 50 (6,85\%). Pada keempat kelompok umur lainnya yaitu pada kelompok umur 38-47, 48-57, 58-67, dan 67-77 tahun molar ketiga maksila lebih sering mengalami impaksi dengan masing-masing impaksi yang terjadi yaitu sebanyak $52(7,13 \%)$, $25(3,42 \%), 19(2,60 \%)$, dan $7(0,96 \%)$ gigi impaksi dibandingkan gigi molar ketiga mandibula dengan gigi impaksi pada setiap kelompok umur masing-masing yaitu 29 $(3,97 \%), 15(2,05 \%), 11(1,50 \%)$, dan $4(0,54 \%)$ gigi impaksi sehingga secara keseluruhan gigi molar ketiga maksila lebih banyak mengalami impaksi dibandingkan gigi molar ketiga mandibula.

Selain gigi molar ketiga baik pada maksila maupun mandibula, terdapat gigi impaksi lainnya yaitu impaksi gigi molar kedua maksila sebanyak $2(0,27 \%)$ gigi impaksi pada kelompok umur 38-47 tahun, gigi molar kedua mandibula sebanyak $2(0,27 \%)$ pada kelompok umur 18-27 tahun. Impaksi gigi molar pertama maksila tidak ditemukan pada penelitian ini. Impaksi gigi molar pertama mandibula terjadi pada kelompok umur 18-27 tahun yaitu sebanyak $3(0,41 \%)$ gigi impaksi dimana jumlah yang sama juga terjadi pada impaksi gigi premolar kedua maksila dan mandibula pada kelompok umur yang sama. Selain pada kelompok umur 18-27 tahun, impaksi gigi premolar kedua mandibula juga terjadi pada kelompok umur 28-37 tahun sebanyak $1(0,13 \%)$ gigi impaksi sehingga total gigi impaksi yang terjadi pada gigi premolar kedua mandibula sebanyak $4 \quad(0,54 \%)$ gigi impaksi. Impaksi gigi premolar pertama maksila tidak ditemukan pada penelitian ini. Impaksi gigi premolar pertama mandibula ditemukan pada kelompok umur 18-27 tahun yaitu sebanyak 1 $(0,13 \%)$ gigi impaksi.

\section{PEMBAHASAN}

Hasil penelitian menunjukkan terdapat 304 rekam medis yang termasuk dalam kriteria inklusi penelitian ini, dengan jumlah 115 $(37,82 \%)$ subjek penelitian laki-laki dan 189 $(62,17 \%)$ perempuan. Jumlah gigi impaksi dalam penelitian ini juga lebih banyak. Kasus gigi impaksi pada laki-laki lebih sedikit ditemukan yaitu sebanyak 264 (36,21\%) dibandingkan pada perempuan dengan gigi impaksi sebanyak 465 (63,78\%). Hal ini menunjukkan impaksi lebih sering terjadi pada perempuan dibandingkan laki-laki. Beberapa penelitian sebelumnya juga mendapatkan hasil yang serupa. Penelitian yang dilakukan oleh Fardi dkk pada tahun 2011 menunjukkan dari total 170 pasien yang diperiksa terdapat 92 $(54,1 \%)$ perempuan yang mengalami gigi impaksi dibandingkan pada subjek laki-laki yang hanya $78(45,9 \%)$. Nilai persentase gigi impaksi pada perempuan juga lebih tinggi dibandingkan pada laki-laki yaitu $70(41,2 \%)$ berbanding 59 $(34,7 \%)$ gigi pada impaksi yang terjadi hanya pada 1 gigi, dan $17(10 \%)$ berbanding $14(8,2 \%)$ pada impaksi yang terjadi pada 2 gigi. Penelitian lain yang dilakukan oleh Aktan dkk juga menunjukkan hal yang sama dimana dari total 5000 subjek penelitian yaitu berupa gambaran radiografi pasien yang berkunjung ke Bagian Oral Diagnosis dan Radiologi Universitas Selcuk terdapat total 147 pasien yang mengalami gigi impaksi dengan perbandingan 101 pada pasien perempuan dan 46 pada pasien laki-laki. Berbagai faktor dapat menjadi penyebab dalam hal ini. Daya tekanan akibat pengunyahan, bentuk makanan, proporsi besar gigi dan besar rahang dapat berperan penting dalam hal ini. Tekanan kunyah laki-laki cenderung lebih besar dibandingkan pada perempuan sehingga akan berpengaruh pada tumbuh kembang rahang nantinya. Bentuk makanan juga dapat berpengaruh pada perkembangan dimana perempuan cenderung suka makan makanan yang lembut dan tidak membutuhkan tenaga atau tekanan kunyah yang besar dibandingkan laki-laki. ${ }^{9,18}$

Gigi impaksi berdasarkan elemen gigi 
Berdasarkan hasil penelitian pada tabel 3 diketahui impaksi gigi pada penelitian ini paling banyak terjadi pada gigi molar ketiga maksila yaitu sebanyak $367(50,34 \%)$ gigi impaksi pada maksila diikuti oleh gigi molar ketiga mandibula sebanyak 337 (46,22\%) gigi impaksi sehingga total gigi molar ketiga yang impaksi baik pada maksila dan mandibula adalah sebanyak 704 $(96,56 \%)$ gigi impaksi. Hal ini menunjukkan baik pada maksila maupun mandibula, molar ketiga merupakan gigi yang paling sering mengalami impaksi. Beberapa penelitian sebelumnya juga mendapatkan hasil yang sama. Afify dan Zamawi dalam penelitiannya pada tahun 2012 menemukan hasil yang sama dimana dari total 186 gigi impaksi terdapat 140 gigi molar ketiga yang impaksi baik pada maksila maupun mandibula. Penelitian yang dilakukan oleh Chu dkk juga mendapatkan hasil yang sama dimana molar ketiga merupakan gigi yang paling sering mengalami impaksi. Dari total keseluruhan gigi impaksi yang ditemukan dalam penelitian mereka yaitu sebanyak 3853 gigi impaksi, 3778 (98,05\%) gigi merupakan impaksi pada molar ketiga baik pada maksila maupun mandibula. Beberapa faktor dapat menjadi penyebab dalam hal ini. Menurut Fotek, lokasi erupsi sempit yang diakibatkan oleh overcrowded gigi atau proporsi besar lengkung rahang yang tersedia dengan besar gigi misalnya lengkung rahang yang terlalu kecil dibandingkan besar ukuran gigi yang ada dapat menjadi beberapa penyebab terjadinya impaksi gigi molar ketiga baik pada maksila maupun mandibula. Pada penelitian ini, penulis tidak melakukan pemeriksaan secara komprehensif dimana penulis hanya melakukan pemeriksaan rekam medis pasien sehingga analisis penyebab impaksi tidak dapat dipaparkan lebih lanjut., ${ }^{8,21}$

Dalam penelitian yang dilakukan oleh penulis, ditemukan impaksi pada gigi molar kedua baik pada maksila maupun pada mandibula dalam jumlah yang sama yaitu 2 $(0,27 \%)$. Selain itu, impaksi gigi juga ditemukan pada gigi lainnya yaitu molar pertama mandibula sebanyak $3(0,41 \%)$, premolar kedua maksila $3(0,41 \%)$ dan mandibula $4(0,54 \%)$, premolar pertama mandibula $1(0,13 \%)$, kaninus maksila $2(0,27 \%)$ dan mandibula $1(0,13 \%)$, insisivus lateral maksila $2(0,27 \%)$, mandibula 3 $(0,41 \%)$ dan sentral baik pada maksila maupun mandibula sebanyak 1(0,13\%). Beberapa penelitian lainnya juga mendapatkan hasil yang tidak jauh berbeda. Penelitian yang dilakukan oleh Aktan dkk mendapatkan dari total 147 gigi impaksi, terdapat 87 impaksi gigi kaninus maksila, 23 kaninus mandibula, 10 gigi premolar kedua mandibula, 9 premolar kedua maksila, 3 premolar pertama pada masing-masing baik maksila maupun mandibula, dan mendapatkan 1 gigi pada keseluruhan gigi insisivus baik lateral maupun sentral maksila maupun mandibula.

\section{KESIMPULAN}

Total rekam medis pasien yang berkunjung ke BP-RSGM UNSRAT Manado yang digunakan sebagai subjek penelitian ini adalah sebanyak 304. Impaksi lebih banyak terjadi pada perempuan yaitu sebanyak 189 dibandingkan pada laki-laki sebanyak 115. Impaksi gigi paling banyak terjadi pada gigi molar ketiga maksila dengan jumlah gigi impaksi sebanyak 367 (50,34\%) impaksi gigi molar ketiga mandibula sebanyak 337 $(46,22 \%)$. Impaksi gigi juga ditemukan pada gigi lainnya yaitu molar pertama mandibula sebanyak $3(0,41 \%)$, premolar kedua maksila $3(0,41 \%)$ dan mandibula 4 $(0,54 \%)$, premolar pertama mandibula 1 $(0,13 \%)$, kaninus maksila $2(0,27 \%)$ dan mandibula $1(0,13 \%)$, insisivus lateral maksila $2(0,27 \%)$, mandibula $3(0,41 \%)$ dan sentral baik pada maksila maupun mandibula sebanyak $1(0,13 \%)$. Impaksi gigi tidak ditemukan pada gigi molar pertama maksila dan premolar pertama maksila.Impaksi gigi paling banyak terjadi pada maksila yaitu sebanyak $377(51,72 \%)$ dibandingkan pada mandibula sebanyak 352 $(48,28 \%)$.

\section{DAFTAR PUSTAKA}

1. Balaji SM. Textbook of oral and maxillofacial surgery. New Delhi: Elsevier; 2007. p 230-40

2. Kulkarni D, Kshirsagar K. The unerupted/impacted teeth: a critical appraisal 
of their pathologic potential- a clinical study. JIDA 2011 April; 5 (4): 483-5

3. Nazir R, Amin E, Jan HU. Prevalence of impacted and ectopic teeth ini patients seen in a tertiary care centre. Pak. Oral Dent. J. 2009; 29 (2): 297-300

4. Zeitler DL. Management of impacted teeth other than third molars. In: Miloro M, Ghali GE, Larsen PE, Waite PD, editors. Peterson's principles of oral and maxillofacial surgery. $2^{\text {nd }}$ edition. Hamilton: BC Decker; 2004. p 131-2.

5. Ahlqwist M, Grondahl HG. Prevalence of impacted teeth and associated pathology in middle-aged and older swedish women. Community Dent Oral Epidemiol 1991; 19: 119-9

6. Stanley HR, Alattar M, Collett WK, Stringfellow HR Jr, Spiegel EH. Pathological sequelae of "neglected" impacted third molars. J Oral Pathol 1988; 17: 113-7

7. Shah RM, Boyd MA, Vakil TF. Studies of permanent tooth anomalies in 7.886 canadian individuals. I: impacted teeth. Dent J 1978;44:262-4

8. Chu FCS, Li TKL, Newsome PRH, Chow RLK, Cheung LK. Prevalence of impacted teeth and associated pathologies-a radiographic study of the hong kong Chinese population. Hong Kong Med J 2003 June ; 9(3): $158-63$

9. Aktan AM, Kara S, Akgunlu F, Malkoc S. The incidence of canine transmigration ad tooth impaction in a turkish subpopulation. Eur J Orthod. 2010 October; 32 (5): 575-81

10. Torres-Lagares D, Florez-Ruiz R, InfanteCossio P, Garcia-Calderon M, GutierrezPerez JL. Transmigration of impacted lower canine: case report and review of literature. Medicina Oral Patologia Oral Cirugia Bucal $200611 ; 171-4$
11. Daskalogiannakis J, Piedade L, Lindholm TC, Sándor GK, Carmichael RP. Cleidocranial dysplasia: 2 generation of management. J Can Dent Assoc. 2006 May; 72(4): 337-42

12. Afify AR, Zawawi KH. The prevalence of dental anomalies in the western region of saudi arabia. ISRN Dentistry 2012 April.

13. Anonymous. Classification of 3rd molar (wisdom teeth) impaction. Available from URL: http://www.exodontia.info/ Wisdom_Tooth_Impaction_Classification .html

14. Anonymous. Impacted mandibular 3rd molar classification, complications, indications for surgical removal, assessment and surgical removal. Available from URL: http://dentistryandmedicine.blogspot.com/20 11/09/impacted-mandibular-3rd-molar.html

15. McDonald RE, Avery DR, Dean JA. Dentistry for the child and adolescent. St. Louis: Mosby Inc; 2004. p.177

16. Hidajat S, Alwi S, editors. Manual rekam medis. Konsil Kedokteran Indonesia 2006. $3-13$

17. Mahsidin A. Gambaran rekam gigi anggota kepolisian republik indonesia daerah Sulawesi utara. Skripsi. Universitas Sam Ratulangi 2012: 5-8.

18. Fardi A, Kondylidou-Sidira A, Bachour Z, Parisis N, Tsirlis A. Incidence of impacted and supernumerary teeth- a radiographic study in a north greek population. Med Oral Patol Oral Cir Bucal 2011 Januari 1;16 (1): e56-61.

19. Dachi SF, Howell FV. A survey of 3874 routine full mouthradiograph: II. a study of impacted teeth. J Oral Maxillofac Surg 1961;14:1165-9.

20. Kramer RM, Williams AC. The incidence of impacted teeth. a survey at harlem hospital. 
Oral Surg Oral Med Oral Pathol 1970;29:237-4

21. Fotek Paul. Impacted tooth [serial online] [cited 23 October 2012]. Available from URL:

http://www.nlm.nih.gov/medlineplus/ency/a rticle/001057.htm 